\title{
ANÁLISE DE EPISÓDIOS DE REESCRITA REVELADORES DA CONSTRUÇÃO DE UM ESTILO
}

\author{
Raquel Salek Fiad
}

\begin{abstract}
RESUMO: This paper discusses some aspects of the acquisition of written language, with emphasis on the acquisition of style. Based on a indiciary paradigm, some particular aspects of the construction of written language are presented. The methodology includes the comparison of different texts with different versions written by the same author.
\end{abstract}

PALAVRAS-CHAVE: aquisição da escrita, estilo, paradigma indiciário, narrativa.

1. Neste trabalho ${ }^{1}$ pretendo apresentar algumas das reflexões que venho realizando como parte do projeto de pesquisa intitulado Estudo da reescrita de textos como indicador dos processos presentes na escrita, que está inserido no Projeto Integrado A relevância teórica dos dados singulares na aquisição da linguagem escrita (CNPq, proc. 521837/95-2) ${ }^{2}$.

Inicialmente, recuperarei alguns pressupostos teóricos e metodológicos do Projeto Integrado (que são, obviamente, assumidos no projeto individual), para, em seguida, explicitar as questões que serão focalizadas a partir da análise de alguns dados de aquisição da escrita.

Conforme já assumido em outros trabalhos anteriormente realizados por mim e pelas demais integrantes do projeto (FIAD, 1993a e 1994; ABAURRE et alii., 1992, 1995a e 1995b), vimos adotando os pressupostos teórico-metodológicos de um paradigma indiciário em nossas reflexões, por considerarmos que, a partir desse olhar, tornam-se reveladores e significativos aspectos singulares e particulares da aquisição da escrita que são considerados marginais em uma perspectiva teórica que valorize os aspectos generalizantes e normais, que ocorrem em paradigmas como o galileano. Os textos do historiador Carlo Ginzburg (GINZBURG, 1939) recuperam, para as ciências humanas, a possibilidade de, através da análise de pistas, sinais, examinar os pormenores, as marcas individuais presentes nas atividades humanas, dentre elas a linguagem.

No caso específico da aquisição da escrita, consideramos especialmente interessante trabalhar com o paradigma indiciário por ele nos permitir lidar com as diferenças mais do que com as semelhanças, com os fenômenos anormais mais do que com a norma, com a possibilidade de ir em busca de explicações, mais do que tentar encontrar evidências para explicações já existentes, dentro de uma perspectiva científica galileana, "do que é individual não se pode falar" (GINZBURG, 1939, p.156), já que a quantificação e a repetibilidade dos

\footnotetext{
Raquel Salek Fiad é professora do Instituto de Estudos da Linguagem da UNICAMP.

${ }^{1}$ Este texto foi apresentado durante o XI Congresso Internacional da Associação de Lingüística e Filologia da América Latina, realizado em julho/1996, em Las Palmas de Gran Canaria, Espanha.

2 Este Projeto Integrado é coordenado pela colega Maria Bernadete M. Abaurre e dele participam, atualmente, três pesquisadoras, três bolsistas de IC, uma de aperfeiçoamento e vários estudantes de pós-graduação, todos do Instituto de Estudos da Linguagem/Unicamp.
} 
fenômenos são fundamentais para um conhecimento científico rigoroso. No entanto, esse rigor não é o esperado para as situações em que "a unicidade e o caráter insubstituível dos dados são, aos olhos das pessoas envolvidas, decisivos" (id., p.178).

2. Dentro do tema específico deste texto, é particularmente relevante a contribuição do paradigma indiciário para a análise da construção de um estilo de escrita.

Retomo aqui as considerações de Bakhtin sobre estilo ao discutir as relações entre os enunciados e os gêneros do discurso (BAKHTIN, 1992). Bakhtin salienta, de um lado, a individualidade do enunciado (visto como o lugar onde a língua se realiza) e, por outro, a variedade dos gêneros do discurso, que se relacionam às diferentes esferas das atividades humanas. O estilo está ligado ao enunciado e aos gêneros do discurso pois, por um lado, o enunciado é individual, isto é, possui um estilo individual, mas, por outro, nem todos os gêneros do discurso favorecem essa manifestação do individual nos enunciados. $O$ estilo, entendido como a seleção dos recursos lingüísticos feita a partir das possibilidades oferecidas pela língua, não pode, portanto, ser estudado independentemente do gênero do discurso. Finalmente, tanto a escolha dos gêneros como a escolha do estilo do enunciado (ou seja, dos recursos lingüísticos) são decorrência da assunção de que cada enunciado tem autor e destinatário.

Em trabalhos realizados anteriormente (MAYRINK-SABINSON, 1993; ABAURRE, 1993; FIAD, 1993b e POSSENTI, 1993) discutimos a relação entre estilo e aquisição da escrita, defendendo o ponto de vista de que há indícios da individualidade - estilo - desde as escritas iniciais. A partir da análise de textos representativos de diferentes momentos da aquisição da escrita, observamos a emergência de traços individuais na escolha dos gêneros discursivos e na seleção dos recursos lingüísticos utilizados desde o início da escrita. Observamos, por outro lado, que o papel da escola na constituição da individualidade vai na contramão desse processo, isto é, há a produção de um estilo escolar que visa à homogeneização. É importante lembrar que assumimos, nesse trabalho, a concepção de estilo como resultado do trabalho que o sujeito realiza com a língua, ou seja das escolhas realizadas.

Neste texto, pretendo discutir as marcas de construção do estilo, ou da construção da individualidade na escrita, a partir da análise de diversos textos de um autor, levando em conta as marcas de reelaboração presentes nos textos. A comparação de diferentes momentos da escrita de um texto bem como a comparação de diferentes textos de um mesmo autor permitirão o levantamento de marcas que indiciam o trabalho que o autor vai realizando com a linguagem. É a construção do estilo que permitirá falar em construção do autor.

Serão analisados três textos de um estudante de $3^{\mathrm{a}}$ série de segundo grau de uma escola pública da cidade de Americana, São Paulo (neste trabalho, M. se refere ao estudante autor dos textos). Esses textos, produzidos em contexto escolar, foram coletados pela professora, que, no momento, desenvolvia também um trabalho de pesquisa sobre a escrita de alguns de seus alunos. Foram selecionadas para este trabalho tanto a versão final de cada texto como todas as versões anteriores (anotações e rascunhos). Todos os textos analisados são narrativas, que foram produzidas a partir de diferentes propostas feitas pela professora. Resumo, abaixo, as informações sobre cada um dos três textos ${ }^{3}$ :

Texto 1

- título: "Zé”

- situação de produção: a partir de uma discussão oral realizada em classe, após a leitura de um texto, cujo tema era o mal-entendido provocado pela linguagem

- versões: quatro

Texto 2

- título: "O inesperado"

\footnotetext{
${ }^{3}$ No correr deste trabalho, os textos analisados serão referidos como 1, 2 e 3. Desse modo, nos exemplos citados, o número entre parênteses após o trecho refere-se ao texto de onde o exemplo foi extraído.
} 
- situação de produção: a partir da apresentação, pela professora, de um conjunto de características de um personagem feminino

- versões: duas

Texto 3

- título: "O meu avô"

- situação de produção: a partir de um fragmento de um texto que é parte da história de uma família, com a recomendação de que a narração deveria ser feita em $1^{\mathrm{a}}$ pessoa

- versões: três

Para o objetivo deste trabalho, decidi deter-me na análise de alguns dos textos de um único autor, deixando de lado, neste momento, os demais textos dissertativos e argumentativos (cartas) desse autor, bem como todos os textos dos outros alunos da mesma classe. Este recorte é justificado pela questão que me propus perseguir aqui: a constituição de um estilo a partir das marcas individuais.

3. Cabe ainda uma justificativa a respeito da relevância do estudo de diferentes versões de um texto ou das marcas de reelaboração presentes em um texto. Os estudos de aquisição da escrita preocupados com o processo têm olhado com especial atenção para esses materiais, entendendo que a análise dos manuscritos permite reconstruir o trabalho de enunciação escrita. Bastante ilustrativos quanto a esse tipo de análise são os trabalhos desenvolvidos por Fabre (1986, 1987, 1989 e 1992), geralmente baseados em manuscritos infantis. Por outro lado, a análise de manuscritos literários, que tem como objetivo a gênese dos textos, também parte da observação de estados intermediários de escrita, de modo a depreender como um autor constrói o seu texto. É nesse segundo grupo de análises que a questão do estilo é enfatizada, enquanto que tende a ser menosprezada quando se trata de textos infantis.

Um exemplo de análise de manuscritos literários que nos permite perceber a preocupação com a construção estilística é o artigo de Fuchs, Gréssillon e Lebrave (1991), cujos autores analisam os manuscritos de um conto de Flaubert. Nesse texto, a análise das reformulações efetuadas por Flaubert permite entrever um estilo de construção textual, que não é exclusivo de Flaubert mas não é também único a todos os escritores.

Em trabalhos realizados anteriormente (FIAD, 1991, 1993a e 1994), tentei apontar, a partir das marcas de reelaboração presentes nos textos, o trabalho que diferentes escritoresestudantes vão realizando com a escrita. No presente trabalho, a análise de um único autor reflete a preocupação atual com a construção do estilo.

4. A análise que passo a apresentar foi realizada a partir da leitura dos três textos em suas respectivas versões, buscando algumas marcas da escrita de M. que permitem a discussão de como esse autor, nesse momento de sua vida e de suas escritas, operou sua seleção dos recursos da língua. Para esta apresentação, serão selecionados alguns dos aspectos que me chamaram a atenção ao ler os textos com o objetivo acima mencionado. Como os três textos, com suas versões, são narrativos, os aspectos discutidos estão relacionados a esse tipo de texto.

Cabe mencionar que, dos três textos aqui analisados, somente um deles, o terceiro, foi solicitado como narração, pela professora. Os demais não tiveram qualquer determinação quanto ao gênero. M. selecionou o gênero narrativo para essas duas produções, diferentemente de outros colegas da classe que escreveram textos dissertativos a partir da solicitação e das informações fornecidas pela professora. Chama também a atenção do leitor que os textos dissertativos de $M$. (que não serão aqui analisados) não apresentam o mesmo tipo de envolvimento com a escrita presente nos narrativos, tanto pela inexistência de mais de uma versão para cada texto, como pela ausência de marcas que indiciem uma maior exploração dos recursos lingüísticos, características essas presentes nos textos narrativos.

Com essa breve introdução, pretendo levantar uma questão sobre a escolha do gênero do discurso e o domínio do mesmo. No caso de M., podemos supor uma relação direta entre o gênero escolhido e mais trabalhado - a narração - e o domínio que demonstra ter nas seleções 
que opera. Na realidade, estou retomando aqui Bakhtin ao afirmar que a primeira seleção efetuada é a do gênero:

O querer-dizer do locutor se realiza acima de tudo na escolha de um gênero do discurso. Essa escolha é determinada em função da especificidade de uma dada esfera da comunicação verbal, das necessidades de uma temática (do objeto do sentido), do conjunto constituído dos parceiros, etc. Depois disso, o intuito discursivo do locutor, sem que este renuncie à sua individualidade e a sua subjetividade, adapta-se e ajusta-se ao gênero escolhido, compõe-se e desenvolve-se na forma do gênero determinado. (BAKHTIN, 1992, p. 301).

No entanto, o trabalho do autor a partir de um dado gênero pressupõe um conhecimento do gênero:

A maior parte desses gêneros se presta a uma reestruturação criativa (de um modo semelhante aos gêneros literários e, alguns deles, num grau ainda mais acentuado), mas um uso criativo livre não significa ainda a recriação de um gênero: para usá-los livremente, é preciso um bom domínio dos gêneros. (id., p. 303).

Estas reflexões de Bakhtin permitem pensar também em textos de autores não literários e estudantes, como é o caso de M.. Entendo que podemos dizer que o autor opera uma seleção do gênero do discurso também em função do domínio que ele tem dos gêneros. Mais ainda, quanto maior o domínio desse gênero, maior o trabalho que o autor efetua nas demais seleções que vai realizando durante a sua escrita (seleções quanto aos aspectos textuais, gramaticais, lexicais).

É com base nessa suposição que a análise dos textos narrativos de M. foi realizada. Desse modo, as reelaborações presentes nas diferentes versões de seus textos são entendidas como momentos reveladores das escolhas e decisões que M. vai operando ${ }^{4}$.

5. O trabalho de Labov e Waletzky (1967) nos fornece alguns critérios para a identificação das unidades narrativas e é tomado, aqui, como uma referência para a discussão dos textos narrativos de M., já que é justamente a exploração do gênero narrativo pelo autor que será apresentada.

Ao tomar a análise feita por Labov e Waletzky, não pretendo discutir a adequação ou não dos textos de $\mathrm{M}$. à estrutura e às características da narrativa apontadas por esses dois autores. Pretendo tomá-los como um ponto de partida para as reflexões sobre as narrativas de M., discutindo os aspectos que mais me chamaram a atenção.

Em todas as narrativas de M., o narrador é um personagem de destaque e todas são feitas na $1^{\mathrm{a}}$ pessoa, o que pode ser notado logo na orientação das narrativas 2 e 3 :

"Às vezes, penso que Suzana nada sabe sobre ecologia. Não sei, age com pretensão, sempre diz sobre os livros relacionados a esta matéria que ultimamente vem lendo..." (2)

"Durante toda minha vida quis sempre descobrir o que fez vovô sofrer tanto!" (3)

E na complicação da narrativa 1:

"Certo dia, estava em casa e precisava urgentemente de um livro que só o meu vizinho, o Zé, possuía." (1)

É importante notar que somente a narrativa 3 teve essa solicitação explícita. Nas narrativas 1 e 2, o eu que narra está presente desde as primeiras versões. No entanto, nas duas primeiras versões da narrativa 3, o eu está ausente:

"Durante toda uma vida, Vicente Brás escondera o motivo pelo qual trancou seu coração / e se isolou do mundo." (3)

Neste caso, a primeira escolha do autor foi alterada em função da recomendação de que "a narrativa deverá ser em $1^{a}$ pessoa". M. escreveu duas versões com o narrador ausente da narrativa e introduziu o narrador na última versão, atendendo à solicitação (ou ordem!) feita.

\footnotetext{
${ }^{4}$ Destaco aqui esta observação porque, para a escola, a existência de marcas de reelaboração evidencia mais o desconhecimento do autor do que o domínio dos recursos que explora. Minha interpretação da existência de várias versões e de reelaborações vai, portanto, no sentido oposto ao da escola.
} 
Uma possibilidade de interpretação para as escolhas de M. seria supor sua preferência por narrar na $1^{\mathrm{a}}$ pessoa, o que sugeriria que a mudança na narrativa 3 não se deu apenas por obediência ao que lhe foi pedido, já que sua escolha, nos outros casos, não pode ser atribuída à obediência, mas a uma decisão própria.

M. inicia seus textos com pouca orientação e entra logo na complicação. O texto 2 foi produzido a partir da apresentação, pela professora, das características de um personagem feminino e é o texto que contém um trecho de orientação:

"Às vezes penso que Suzana nada sabe sobre ecologia. Não sei, age com pretensão, sempre diz sobre os livros relacionados a esta matéria que ultimamente vem lendo, e fica horas para mostrar-me que se esforça muito para me agradar. Não agüento mais, ela fica o dia inteiro em casa e geralmente se mete em meus assuntos e em minhas coisas. Acredita que agora ela deu de beliscar meu irmão mais novo? Ela fica nervosinha quando o pequeno se tranca no banheiro e fica cantando. Ora! Se ela quer por ordem, que ponha, mas na casa dela! Não estou entendendo onde ela quer chegar. Parece que ela me segue, até em minhas opiniões, algumas vezes até mostra falta de personalidade. Não sei onde vai parar minha paciência, quando eu me encher de tudo isso!"

Dentre as características para o personagem, fornecidas pela professora, constavam: quer entrar para movimento ecologista, adora crianças até 3 anos de idade, irrita-se com porta de banheiro trancada, dentre outras. Provavelmente M. dedicou-se a nos apresentar o personagem Suzana no início de seu texto, diferentemente do que fez nos outros, para cumprir o que lhe foi solicitado. É importante notar que, nos textos 1 e 2, não houve reformulações nessa parte dos textos de M.. No texto 3, devido à mudança ele/eu, temos as seguintes versões: "Durante toda uma vida, Vicente Brás escondera o motivo pelo qual trancou seu coração e se isolou do mundo." (1 ${ }^{\mathrm{a}}$ versão)

"Durante toda uma vida, Vicente Brás escondera o motivo pelo qual trancou seu coração." (2a versão)

"Durante toda minha vida quis sempre descobrir o que fez vovô sofrer tanto!" ( $3^{\mathrm{a}}$ versão)

No início da complicação de seus textos, M. introduz algum elemento que vai permitir, para o leitor, perceber já a trama que vai provocar o desenrolar de sua narrativa. No texto 1 , temos, na última versão:

"Chegando, fui muito bem tratado e recebido pela sua mãe, que apesar de cansada conseguiu me agradar com seus doces e sucos. Só que logo recebi a triste notícia que o Zé estava doente! Tinha apenas febre mas não estava tão mal!"

É interessante compararmos essa versão com as anteriores:

"Chegando, fui muito bem tratado e recebido pela sua mãe, que me agradou com seus doces e sucos. Só que logo recebi a notícia que o Zé estava doente! Tinha febre mas não estava tão mal!"

O acréscimo de apesar de cansada e do adjetivo triste diante de notícia antecipa ao leitor o problema que vai ser anunciado a seguir: a doença do Zé.

No texto 2, o autor introduz o elemento que vai conduzir a narrativa: a briga entre os personagens.

"Pensei que ficaria livre nesta viagem, e fiquei, só que logo quando cheguei em casa encontrei de cara Suzana e o meu quarto, sabe como?" (2 versão)

"Pensei que ficaria livre! Considerei aquilo um 'fora'! Mas não, quando voltei para casa encontrei meu quarto sabe como?" ( $1^{\mathrm{a}}$ versão)

Nesse texto, o autor se dirige explicitamente ao seu leitor, inserindo as informações já com um certo espanto, com a intenção de provocar, também no leitor, o estranhamento que o personagem vai tendo:

"Acredita que agora ela deu de beliscar meu irmão mais novo?"

"Inacreditável, não?" 
“... sabe como?"

No texto 3, a referência ao cartão e à chave, logo no início, permite ao leitor perceber que esses são elementos complicadores da narrativa:

"Vasculhando suas coisas certo dia, encontrei uma chave grande, a qual despertou a minha curiosidade! Ela estava dentro de um casaco muito preto e antigo, o qual nunca vira em vovô. Simplesmente esqueci deste objeto que aparentava ser insignificante, mas ao mesmo tempo não." ( $3^{\mathrm{a}}$ versão)

"Morreu no dia 27 de agosto de 1891 com um cartão escrito em alemão, morreu sentado no sofá da sala! Sua morte, repentina, abalo seus poucos parentes e amigos. Eu estava com apenas 15 anos e lembro-me que na época aquele cartão despertou-me algo." ( $3^{a}$ versão)

Nas versões anteriores, temos também a chave como elemento causador da complicação:

"Na tarde, Valéria fuçara nas vestimentas do irmão e encontrou no bolso de um casaco preto uma chave a qual despertou sua curiosidade"

São esses elementos que vão complicar as narrativas: a doença do Zé, a briga entre os namorados, a chave que permite decifrar o mistério do avô. M. vai conduzindo suas narrativas com esses elementos, num crescendo. Importante nesse processo é o uso que faz de adjetivos e advérbios para caracterizar tanto ambientes e lugares, como pessoas. Destaco, aqui, alguns trechos que ilustram esse uso, apontando que, embora ocorra, muitas vezes, desde a primeira versão, a comparação entre as versões permite notar uma maior elaboração entre elas. $\mathrm{Na}$ narrativa 1, temos trechos que só ocorrem na última versão, trechos que ocorrem sem modificações em todas as versões e, mais freqüentemente, trechos que ilustram o trabalho de M. entre uma e outra versão:

"E lá estava o Zé, esticado, pálido em sua cama...." (só na $4^{\mathrm{a}}$ versão)

“... o responsável por deixar todos da casa naquele estado lastimável de depressão.” (em todas as versões)

"Entrei no quarto, era bagunçado e confuso, roupas por toda a parte, paredes brancas que já estavam aparentando velhas com suas ingentes rachaduras." ( $1^{\mathrm{a}}$ versão)

"Entrei no quarto, era bagunçado e confuso, roupas por toda a parte, paredes que um dia foram brancas e que também aparentavam serem velhas devido às suas ingentes rachaduras." ( $4^{\mathrm{a}}$ versão)

“... e quando cheguei em sua casa, vi sua mãe chorando e tive uma surpresa impressionante!" ( $1^{\mathrm{a}}$ versão)

"Quando cheguei, presenciei uma cena terrível! A mãe do Zé estava sentada no sofá rasgado da sala, chorando! Fiquei ainda mais aterrorizado..." (4 versão)

"Só que logo recebi a notícia que o Zé estava doente!" ( $1^{\mathrm{a}}$ versão)

"Só que logo recebi a triste notícia que o Zé estava doente!" (4a versão)

Nesse texto, ocorrem ainda trechos em que o autor trabalha visando a uma melhor caracterização do ambiente, operando praticamente com os mesmos itens em todas as versões e efetuando deslocamentos entre esses itens:

"Havia um copo com água em seu criado-mudo que estava encostado junto com um abajur em sua cama." (1 $1^{\text {a }}$ versão)

"Havia em seu criado-mudo um copo com água e um abajur, este estava encostado à sua cama." ( $2^{\mathrm{a}}$ e $3^{\mathrm{a}}$ versão)

“... do lado, havia um abajur e um copo com água em cima de uma cadeira velha." (4a versão)

No texto 2 , temos trechos que já ocorrem desde a primeira versão, como os dois primeiros abaixo e trechos que foram-se modificando da primeira para a segunda versão:

"... e ela vestia uma camiseta branca muito grande."

"Ela estava pálida." 
“... passando por um corredor estreito e escuro. Quando cheguei ouvi uma música do Lulu Santos e observei. Bati com minhas mãos trêmulas." ( $1^{\mathrm{a}}$ versão)

"Segui, ele [o corredor] era estreito e escuro, quando cheguei na porta ouvi uma música, era do Lulu Santos, sinal de fossa. Bati com minhas mãos trêmulas." ( $2^{\mathrm{a}}$ versão)

"Ela:" (1 $1^{\text {a }}$ versão)

"Ela imediatamente disse com a voz fraca:" (2 versão)

“... ela pediu à mãe que anotasse o recado." ( $1^{\mathrm{a}}$ versão $)$

“... ela pediu à boa senhora que anotasse o recado." ( $2^{a}$ versão)

"Ela, decidida, levantou a cabeça, chegou bem perto de mim e disse:" ( $1^{\text {a }}$ versão)

"... e Suzana com muito custo levantou a cabeça com os olhos alagados. Ela decidida, aproximou-se de mim e disse:" ( $2^{\mathrm{a}}$ versão)

Finalmente, do texto 3, destaco trechos que se encontram só na última versão, como os três primeiros a seguir, e trechos cuja comparação entre as diferentes versões permitem perceber como M. vai reconstruindo seus textos visando produzir um maior envolvimento com a trama narrada:

"Tal sentimento subiu-me e gelou toda minha alma, inacreditável, inexplicável, altamente inconsciente! A chave surgiu em meu pensamento velozmente e suando frio corri desesperadamente até minha casa." ( $3^{\text {a }}$ versão)

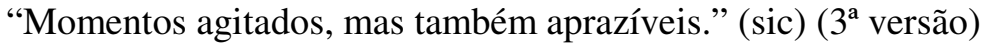

"O choque foi violento, destruidor!" ( $3^{\mathrm{a}}$ versão)

“... e encontrou no bolso de um casaco preto...” ( $1^{\mathrm{a}}$ versão)

"Ela estava dentro de um casaco muito preto e antigo..." ( $3^{a}$ versão)

"Era calado, tinha um olhar desmaiado, triste, o rosto com formas firmes e o corpo magro, cansado." ( $1^{\text {a }}$ versão)

"Vovô sempre foi muito calado e observador, tinha um olhar desmaiado, triste e seu rosto possuía traços de quem já havia passado por muitas coisas." ( $3^{\mathrm{a}}$ versão)

"Desceu a escada, agora com passos leves e seguros..." ( $1^{\mathrm{a}}$ versão)

"Dirigi-me novamente à casa e em passos bem mais seguros desci vagarosamente a escada que finalizava no sótão escuro, sujo, melancólico!" ( $3^{\text {a versão) }}$

Nesse processo de construção da narrativa, M. chega ao ponto de maior complicação de seus textos. Podemos observar, na versão final de cada um dos três textos, que, nesses momentos máximos de complicação, M. utiliza os recursos acima mencionados - maior detalhamento e qualificação de seres, lugares e objetos - visando produzir as cenas mais fortes de suas narrativas:

"Logo depois, resolvi lavar minha bicicleta no quintal e tentar esquecer tudo, só que quando mal comecei, ouvi gritos: O Zé morreu! O Zé morreu! Corri, como nunca, até a casa de meu amigo! Quando cheguei, presenciei uma cena terrível! A mãe do Zé estava sentada no sofá rasgado da sala, chorando! Fiquei ainda mais aterrorizado, não sabia o que fazer e então não suportei a emoção e chorei." (1)

"Nisso, a porta se abriu e ela vestia uma camiseta branca muito grande, que cobria a bermuda.

Ela estava pálida!" (2)

"Dirigi-me novamente à casa e em passos bem mais seguros desci vagarosamente a escada que finalizava no sótão escuro, sujo, melancólico!

Com a caixa na mão pude perceber que não era uma caixa, era um pequeno baú! Mas como fora buscar uma chave que um dia guardei por achá-la interessante, mesmo não sabendo para que ela seria útil! Procurei não pensar e agir como mandava meu coração. Movimentos agitados, mas também aprazíveis. Não sei descrever o que senti realmente, medo, ansiedade, felicidade... talvez um conjunto de tudo isso." (3)

A resolução de seus textos é breve e rápida:

"Foi quando vi o Zé sair do quarto aos berros." (1, 1ª versão) 
"E chorei mesmo, até que pude ver o Zé saindo do seu quarto, também aos berros com o gato morto em seus braços." (1, $2^{\mathrm{a}}, 3^{\mathrm{a}}$ e $4^{\mathrm{a}}$ versões $)$

"Ela, decidida, levantou a cabeça, chegou bem perto de mim e disse:

- Eu te amo!

O meu corpo todo gelara e não conseguia me mover." (2, $1^{\mathrm{a}}$ versão)

"Ela decidida, aproximou-se de mim e disse:

- Eu te amo!

Meu corpo gelou e adormeceu!" (2, $2^{\mathrm{a}}$ versão)

"Leu-a e durante, acredito, uma hora Valéria permaneceu atônita! A carta tinha uma literatura esplêndida e relatava com muita dor a única e antiga paixão de Vicente.” (3, $1^{\mathrm{a}}$ versão)

"E só então percebi que não era uma simples carta, aquele envelope continha informações que explicariam melhor do que tudo o que realmente aconteceu com meu querido avô!..." $\left(3,3^{\mathrm{a}}\right.$ versão)

M. não encerra seus textos aí. Nos textos 2 e 3, inclui uma seção avaliativa:

"Há algum tempo atrás havia percebido que eu, Ricardo, tinha todo esse tempo fechado os olhos e fingido não ver o amor!" ( $2,1^{\mathrm{a}}$ versão)

"Sabe, sinceramente percebi que eu estava me enganando, cometendo uma das piores coisas que pode um ser humano fazer, mentir para si mesmo! Mas o pior era que havia fechado os meus olhos e estava tentando sufocar o único sentimento capaz de encher de felicidade a vida de uma pessoa, o amor!" (2, $2^{\mathrm{a}}$ versão)

"Vovô, foste um campeão apesar de tudo, pois soube amar intensamente e garantir a altivez e a pureza de sua alma! Soube, acima de tudo, viver e como prova maior de resistência, pôde suportar o eterno choro e o rio de lágrimas de seu coração que invadiu-lhe o espírito durante toda a sua vida!" $\left(3,2^{a}\right.$ versão)

Enquanto, nas outras partes dos textos, o trabalho que M. realiza com a linguagem produz efeitos que fazem suas narrativas ganharem tanto na caracterização de personagens, objetos ou locais, como no envolvimento produzido através da trama apresentada, na avaliação, a impressão que se tem é que outros discursos entram no texto de M. - o lugar comum, o clichê tomam o lugar do texto que vinha sendo elaborado. Podemos dizer que são trechos que nada contribuem para as narrativas, na medida em que, nesse momento, não aparece mais o mesmo tipo de trabalho que M. vinha realizando desde a orientação dos seus textos.

No texto 1, M. termina explicando ao leitor a razão do susto do amigo de Zé, no que é bem sucedido somente ao chegar à quarta versão de seu texto:

"O que eu não sabia é que o gato tinha o mesmo nome que o dono! Fato este que demonstra claramente o afeto que sentia pelo animal. De certa forma, senti um alívio por ver que meu amigo estava 'bem' e que fora o gato o responsável por deixar todos da casa naquele estado lastimável de depressão." (4 versão)

Nas versões anteriores, M. vai tentando fornecer essa explicação, porém sem muito sucesso:

"Na verdade, Zé também era o nome de seu querido gato (resolveu dar esse nome quando ganhou o animal pois o afeto era realmente grande), o responsável por deixar o dono naquele estado lastimável, compartilhando com o sofrimento de seu animal, que era considerado como uma pessoa da família, e ainda por cima, muito querida." ( $1^{\text {a }}$ versão)

"O que eu não sabia é que há algum tempo atrás meu amigo havia ganhado este gato, que recebeu o seu próprio nome devido ao enorme afeto que sempre sentiu pelo seu animal de estimação! Sendo assim, não imaginava que o gato era tão importante para ele e que possuíam o mesmo nome! De certa forma senti um alívio por ver que meu amigo estava 'bem' e que fora o gato o responsável por deixar todos da casa naquele estado lastimável de depressão." ( $2^{\mathrm{a}}$ versão) 
"O que eu não sabia é que há algum tempo atrás meu amigo havia ganhado este gato, que recebeu o seu próprio nome devido ao enorme afeto que sempre sentiu pelo seu animal de estimação! Sendo assim, não imaginava que o gato era tão importante para ele e que possuíam o mesmo nome! De certa forma senti um alívio por ver que meu amigo estava 'bem' e que fora o gato (que representava uma pessoa da família) o responsável por deixar todos da casa naquele estado lastimável de depressão." ( $3^{\mathrm{a}}$ versão)

No entanto, o que nos chama mais a atenção nesse trecho é que M. reelabora seu texto, sozinho, de modo a chegar a um resultado que o satisfaz e também ao leitor. De todos os trechos reelaborados por M., este é o que nos permite perceber, com mais nitidez, os problemas que enfrenta com a escrita, as escolhas que efetua. Este trecho também se diferencia das avaliações dos textos 2 e 3, onde não se percebe o trabalho de M. se defrontando com as diferentes possibilidades da língua e tomando suas decisões.

6. O que podemos dizer sobre o estilo de M. a partir da análise de três de seus textos? Em primeiro lugar, a escolha do gênero narrativo por $\mathrm{M}$. e as inúmeras outras escolhas que vai realizando durante suas escritas e reescritas nos permitem ver que M. explora os recursos de ordem textual, lexical e gramatical, o que indica um certo domínio do gênero escolhido. Em segundo lugar, a preferência de M. pelo gênero discursivo decorre do domínio que possui e que lhe permite ser autor de seus textos. Nos momentos não-narrativos de seus textos - as avaliações - M. não exerce o mesmo domínio e não exerce a autoria.

Certamente o domínio que M. tem sobre o gênero narrativo foi sendo adquirido a partir da leitura e escrita de outras narrativas, na escola e fora dela. Esse processo não é exclusivo a M. mas, nesse percurso, M. foi construindo suas marcas pessoais que permitem a um leitor reconhecê-lo nos seus textos.

Esta análise, que permitiu apontar os conhecimentos que M. tem e que aparecem em seus textos, não teve como objetivo apontar o outro lado: o que M. não domina ainda sobre a narrativa, o que poderia ter explorado e não explorou, o não-domínio de outros gêneros. Não era esse o olhar que pretendia ter para os textos de M. Também não pretendi dizer que M. tem o domínio de todos os recursos lingüísticos. Pretendi mostrar que, na aquisição da escrita, há vários caminhos, e o que $\mathrm{M}$. vem percorrendo é um deles.

\section{BIBLIOGRAFIA}

ABAURRE, M.B.M.; MAYRINK-SABINSON, M.L.T.; FIAD, R.S. O caráter singular das operações de refacção nos textos representativos do início da aquisição da escrita. Estudos Lingüísticos; Anais do XXIV Seminário do GEL, São Paulo, 1995a.

The singular nature of rewriting operations in texts representative of the beginning of writing acquisition. Texto apresentado na Seventh Annual Conference on Ethnographic and Qualitative Research in Education. University of Massachusets at Amherst, Amherst, Massachusets, 1995b.

A relevância teórica dos dados singulares na aquisição da linguagem escrita. Texto do Projeto Integrado enviado ao CNPq, 1992.

ABAURRE, M.B.M. Explorando os limites da sistematicidade: indícios da emergência de traços estilísticos na escrita infantil. Estudos Lingüísticos; Anais do XXII Seminário do GEL, Jahu, 1993.

BAKHTIN, M. M. Estética da criação verbal. São Paulo, Martins Fontes, 1992.

FABRE, C. Variantes de reécriture, citations, discours rapportés à l'école élémentaire. Cahiers d'acquisition et de pathologie du langage, n. 9, 1992. 
L' entrée dans l'écriture; comment des écoliers transforment une "histoire". DRLAV, $\mathrm{n}$. 41, 1989.

La réécriture dans l'écriture; le cas des ajouts dans les écrits scolaires. Études de Linguistique Appliquée, n. 68, 1987.

62, 1986.

FIAD, R. S. O estudo de diferentes versões de um texto e a prática escolar. Estudos Lingüísticos; Anais do XXIII Seminário do GEL, São Paulo, 1994.

Um estudo de variantes textuais e sua contribuição ao ensino de língua materna.

Cadernos de Estudos Lingüísticos, Unicamp, n. 24, 1993a.

Estilo e homogeneidade: análise de textos de universitários. Estudos Lingüísticos; Anais do XXII Seminário do GEL, Jahu, 1993b.

Operações lingüísticas presentes nas reescritas de textos. Revista Internacional de Língua Portuguesa, AULP, Lisboa, n. 4, jan. 1991.

FUCHS, C.; Gréssillon, A.; LEBRAVE, J. Flaubert: Ruminer Herodias. Du cognitif-visuel au verbal-textuel. L'écriture et ses doubles. Génèse et variation textuelle. Paris, Ed. du CNRS, 1991.

GINZBURG, C. Sinais: raízes de um paradigma indiciário. In: Mitos, emblemas, sinais. São Paulo, Companhia das Letras, 1989.

LABOV, N.; WALETZKY, J. Narrative analysis: oral versions of personal experience. In: HELM, J. (ed.). Essays in the verbal and visual arts. Seattle/London, University of Washington Press, 1967.

MARTINEZ, R. H.. Três tipos de discurso. São Paulo (Estado) Secretaria da Educação. Coordenadoria de Estudos e Normas Pedagógicas. Subsídios à proposta curricular de língua portuguesa para o $1^{\circ}$ e $2^{\circ}$ graus. São Paulo, SE/CENP, v.1, 1987.

MAYRINK-SABINSON, M.L.T. Indícios de individualidade na escrita inicial da criança. Estudos Lingüísticos; Anais do XXII Seminário do GEL, Jahu, 1993.

POSSENTI, S. Estilo e aquisição da escrita. Estudos Lingüísticos; Anais do XXII Seminário do GEL, Jahu, 1993. 